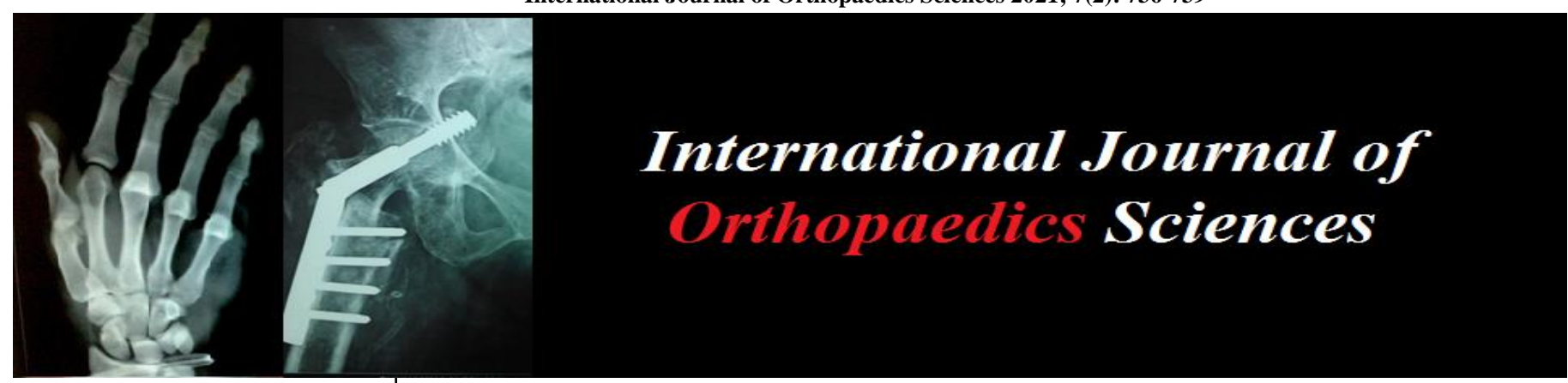

E-ISSN: 2395-1958

P-ISSN: 2706-6630

IJOS 2021; 7(2): 736-739

(C) 2021 IJOS

www.orthopaper.com

Received: 01-02-2021

Accepted: 03-03-2021

\section{BG Saga}

Professor, H.O.D,

Adichunchanagiri Institute of

Medical Sciences,

Adichunchanagiri University

B G Nagar, Nagamangala Taluk,

Mandya, Karnataka, India

Mohammad Ansar

Post-Graduate,

Adichunchanagiri Institute of

Medical Sciences,

Adichunchanagiri University

B G Nagar, Nagamangala Taluk,

Mandya, Karnataka, India

\section{Guruprasad S}

Post-Graduate

Adichunchanagiri Institute of

Medical Sciences,

Adichunchanagiri University

B G Nagar, Nagamangala Taluk,

Mandya, Karnataka, India

\section{Functional outcome of proximal humerus fracture management with proximal humerus internal locking system plate}

\section{BG Sagar, Mohammad Ansar and Guruprasad S}

DOI: https://doi.org/10.22271/ortho.2021.v7.i2j.2696

\section{Abstract}

Background: Proximal humerus fractures are the 2nd most common fractures of upper extremity and one of the most common fractures in osteoporotic bone. $85 \%$ of these fractures are undisplaced or minimal displaced fractures which can be treated with conservative management. $15 \%$ fractures are displaced and unstable and which may need surgical management. The surgical procedure remains a challenging and unsolved problem to the surgeon especially because of its high complication rate. Internal locked plating becoming more popular, to maximize clinical outcome with our experience of surgical procedure in using system pate. In our study, the plate provides stable fixation with a goal of early restoration of a painless shoulder.

Methods: A prospective study was conducted in department of orthopaedics in Adichunchanagiri institute of medical sciences, B.G. Nagara, mandya from June 2018 to August 2020. Displaced Neer's part 2, part 3 or part 4 with age not less than 18 years and not more than 75 years. Twenty patients with proximal Humerus fractures were taken into study, all patients were fixed with PHILOS plate.

Results: Functional outcome evaluated with CONSTANT - MURLEY score, we got excellent results in 04 cases, satisfactory in 09 cases, unsatisfactory in 05 and failure in 02 cases with a mean ConstantMurley score at the end of final follow-up period was around 80.2.

Conclusion: Proximal humeral fractures managed by internal fixation with anatomic locking compression plates yields satisfactory results when provided the correct surgical technique. The anatomic locking compression plate is suitable for the stabilization of proximal humeral fractures (Neer's 2-part, 3part and 4-part fractures and osteoporotic fracture) and can lead to a good functional outcome.

Keywords: proximal humerus fractures, osteoporotic fractures, PHILOS, constant-Murley score

\section{Introduction}

Proximal humerus fractures accounts for approximately $5 \%$ of all fractures and approximately $26 \%$ of humerus fractures. 1 2nd most common upper extremity fracture and the Proximal humerus fracture are 3 rd most common fractures in elderly after hip and distal radius fracture. One of the most common fractures in osteoporotic bone with fall from standing height onto an outstretched upper extremity is the most common mechanism of injury in elderly patients. High- energy trauma as fall from height and motor vehicle accidents or athletic injuries are the most common mechanism in younger patients.

Incidence of 73 cases per 100,000 individuals has been reported per year out of which $85 \%$ are minimally displaced fractures and can be managed conservatively ${ }^{[2]}$ Remaining $15 \%$ are associated with severe displacement that leads to temporary disability and loss of working hours which needs surgical management.

Treating these injuries, from evolution to outcome is controversial and confusion. Due to the complexity and displacements of fractures still exists as an unsolved problem and fixation techniques are myriad and none of these are ideal.3,4 Difficulties in surgery have been multifactorial, including osteoporotic bone, angular instability, implant impingement, bone loss, loss of reduction and backing out of screws. The indication for fixing such a fracture fixation fracture pattern, quality of bone and age and activity of the patient.5 Hence, proper radiographic evaluation for good anatomic results with operative technique.

Studies have shown operative treatment with open reduction and internal fixation is better for
BG Sagar

Professor, H.O.D,

Adichunchanagiri Institute of

Medical Sciences,

Adichunchanagiri University

B G Nagar, Nagamangala Taluk,

Mandya, Karnataka, India 
displaced and unstable fractures with some morbidity and undesirable sequelae.6 Recently, open reduction and internal fixation with locked plating has demonstrated promise in the treatment of displaced, comminuted proximal humerus fractures. This approach offers several potential advantages of stable reduction and stabilization compared with more traditional open techniques ${ }^{[7]}$.

\section{Methods}

This is a prospective study, conducted in the department of Orthopaedics in Adichunchanagiri Institute Of Medical Sciences, B.G. Nagara,

Mandya. All patients with displaced proximal humerus fractures admitted in this hospital from june 2018 to august 2020 were considered for study if they fulfilled following criteria.

\section{Inclusion Criteria}

Patient with following type of proximal humerus fractures.

1. Patients with proximal humerus fractures of part 2, part 3 or part 4.

2. Patients with age more than or equal to 18 years.

3. Patients with age less than 75 years

\section{Exclusion Criteria}

1. Pathological fractures from primary, secondary, and metastatic tumours.

2. Patients with fracture chronic cases.

3. Patients with open fractures

4. Patients who might be unable to cooperate in assessment of function in view of head injury.

5. Patients not fit for surgery due to any pre-existing co morbidity.

6. Injuries older than 21 days.

Fractures aged 18 years or less admitted in the hospital

\section{Surgical Procedure}

The operation is performed under general anesthesia. Patient is placed in supine position. Deltopectoral approach was taken. Then pass through superficial and deep surgical dissection, expose the fracture and reduce the fracture fragments. In comminuted fractures, temporary fixation with $\mathrm{K}$-wires is recommended to hold the fracture reduction. precontoured anatomic locking compression plate is positioned approximately $8 \mathrm{~mm}$ distal to the upper edge of the greater tuberosity. Correct plate position checked and the adequacy of fracture reduction confirmed on fluoroscopic imaging. With the plate appropriately positioned and the fracture reduced, proximal and distal screws are placed in the plate and confirmed with fluoroscopic image. Wound closure done in layers.

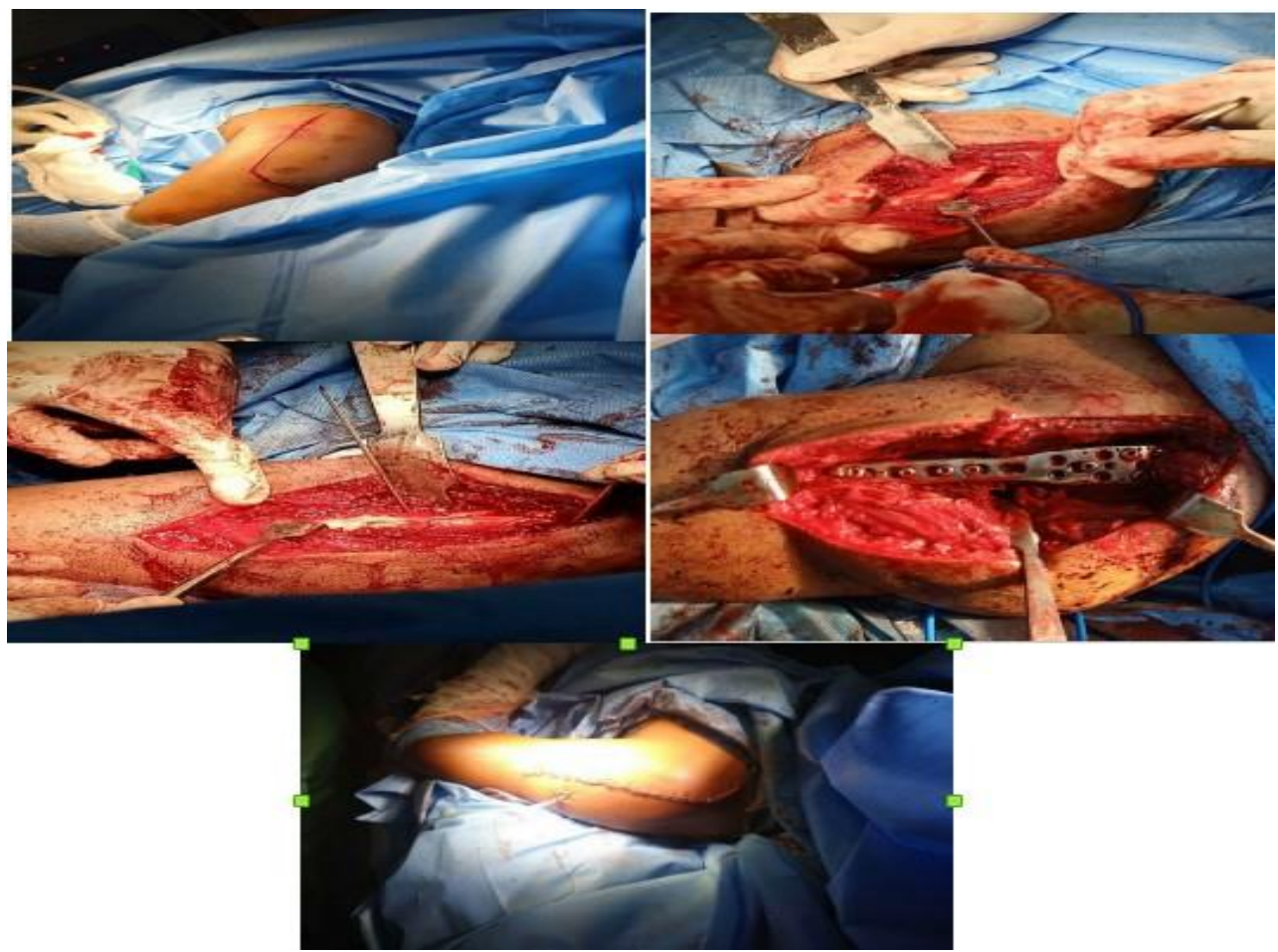

(a) Incision (b) Fracture ends exposed (c) Temporary fixation with k wires; (f) Fixation with PHILOS plate and locking screws; (f) Skin closure

Postoperatively, the arm is immobilized in a shoulder immobilizer. The patient progresses through a three-phase rehabilitation program consisting of

i. Passive or assisted exercises at 2-3 weeks

ii. Active exercises starting at approximately 4-6 weeks

iii. Strengthening or resisted exercises beginning 10 to12weeks after surgery

All the patients were followed up by clinical and radiographic assessment immediately after treatment and at 1,3 , and 6 month. The functional assessment was done according to Constant Murley score.

\section{Observation}

Most Patients admitted were either brought to casualty or through the outpatient department with proper clinical examination elicited and recorded. Radiographic evaluation was done by Neer's trauma series and temporary arm immobilization with shoulder immobilizer. Operative fixation has been done after stabilizing the general condition of patient.

All the cases were approached by deltopectoral approach. Fractures are reduced anatomically and fixed with $3.5 \mathrm{~mm}$ PHILOS plate. Rigidity of fixation was checked on table. Post-operative mobilization was continued in the arm pouch. 
Post-operative second week all patients were encouraged for pendulum exercise. 10th day of post-operative sutures were removed.

No complications were seen during intra-operative except for increased blood loss in three patients. Immediate postoperative complications as post- operative infection was seen in one patient. Late post-operative complications as stiffness noted in three patients to a marked degree and implant failure in two patients.

\section{Results}

A sample of twenty patients of proximal humerus fractures with 14 males and 06 females with ages of patients ranged between 18 - 75 years. The causes were Motor vehicle accident in 12, fall in 07 patients and electric shock in 1 patient. 13 patients had fracture on the right side and 7 patient involved fracture on left. These patients were then followed up for a period of 3 weeks to 6 months.

Functional outcome evaluated with CONSTANT -MURLEY SCORE, we got excellent results in 04 cases, satisfactory in 09 cases, unsatisfactory in 05 and failure in 02 cases with a mean Constant-Murley score at the end of final follow-up period was around 80.2.
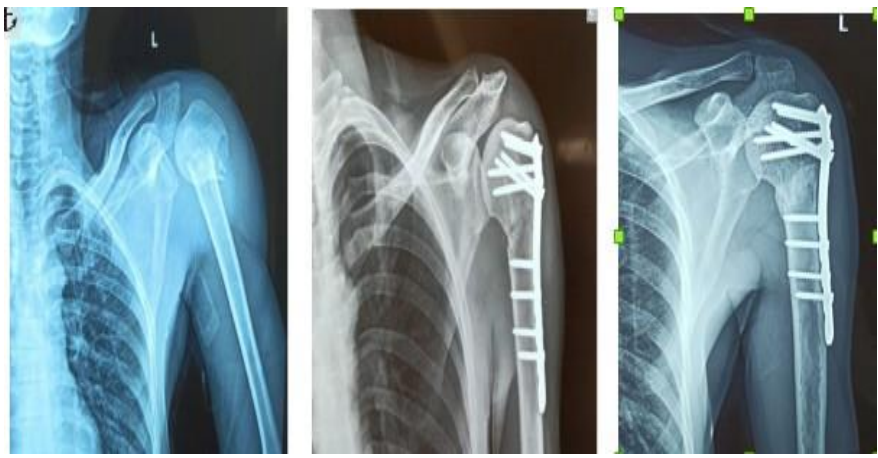

(g) X-ray: pre- op, immediate post op and 6 months follow up

Table 1: Distribution of Neer's Type of fracture of patients studied

\begin{tabular}{|c|c|c|}
\hline Neer's Type of fracture & No. of patients & Percentage \\
\hline 2 Part & 8 & 40.0 \\
\hline 3 Part & 8 & 40.0 \\
\hline 4 Part & 2 & 10.0 \\
\hline Fracture with dislocation & 2 & 10.0 \\
\hline Total & 20 & 100.0 \\
\hline
\end{tabular}

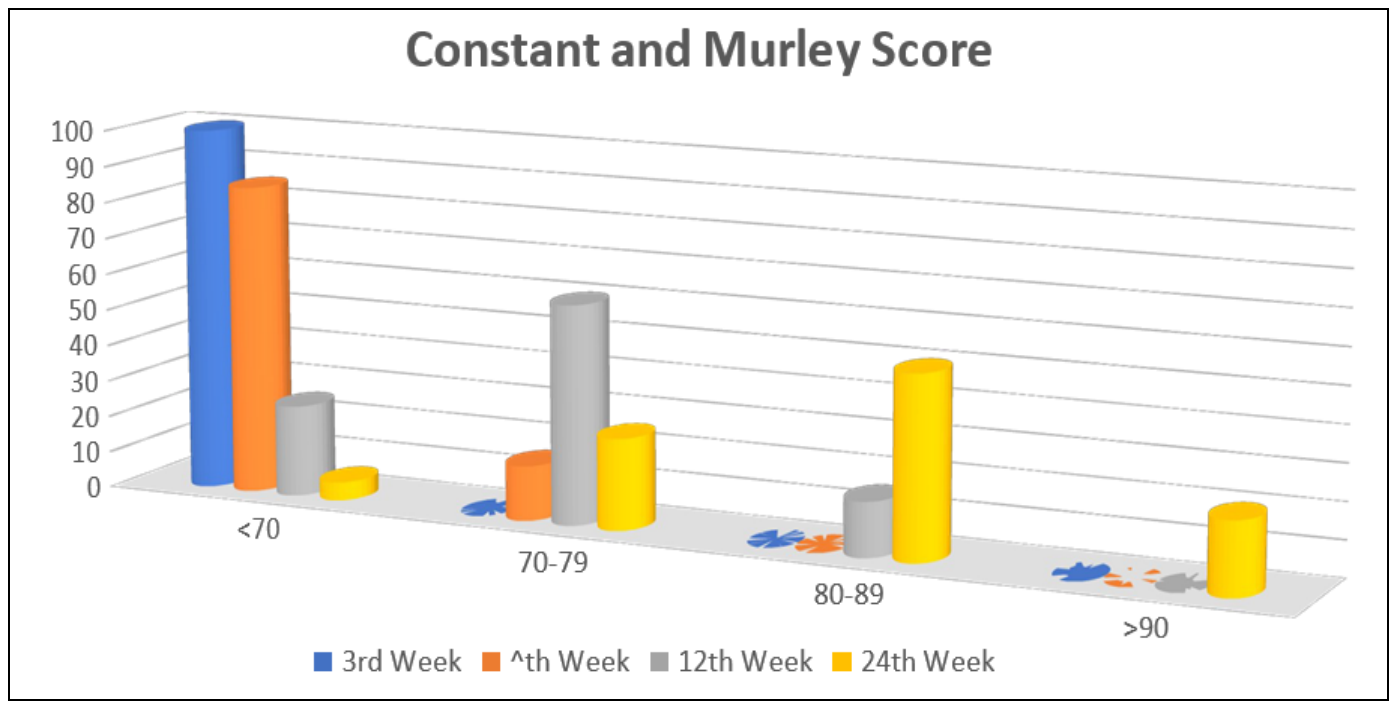

Graph 1: Results according to CMS scoring

\section{Discussion}

Proximal humeral fractures represent an increasing challenge for health-care system because of the increasing proportion of elderly individuals in the population. The majority of patients with these fractures are more than 60 years old, and most these fractures are related to osteoporosis. Nevertheless, stable reduction is essential for healing of these fractures and for achieving early functional recovery of the shoulder. In patients with osteoporotic bones and/or comminuted fractures, operative stabilization is challenging and remains controversial.

Successful outcome after plate osteosynthesis of proximal humerus fractures have been reported.8-10 Open reduction and internal fixation of proximal humerus fractures with nonlocking plates and screws has been shown to provide strongest fixation in non-osteoporotic bone.10 As the stability of osteosynthesis with non- locking plates and screws, relies on the friction between the plate and the bone, the effectiveness of traditional plate and screw fixation decreases with bone quality.

Newer techniques involving the use of locking compression plates and screws with angular stability have been introduced in order to avoid complications

associated with traditional plates. The anatomic locking compression plates (PHILOS: proximal humerus interlocking system) are designed to maintain a stable fracture reduction even in osteoporotic bone. Advantages of these plates include gentle fracture reduction, resistance to screw pull out even in patients with poor bone stock because of the combination of fixed -angle screw -plate locking and three -dimensional placement of screws in humeral head, and possibility of early exercise and a short period of immobilization because of high initial stability achieved ${ }^{[11]}$.

In 2008 Shahid et al. proposed their prospective review of 50 patients treated for proximal humeral fractures with PHILOS plate. 11 patients had 2 part fractures 11 patients had 3 part and18 had four part fractures. Radiological union was achieved in 40 out of 41 (5 patients died and 4 lost the follow up), complications noted in 4 patients. Their study has shown that PHILOS is the reliable implant for proximal humerus ${ }^{[12]}$. In 2009 Brunner et al. evaluated the incidence of complications and functional outcome after open reduction 
and internal fixation with PHILOS. Study was prospective, multicenter study between September 2002 to September 2005, with 158 fractures in 157 patients. They had primary screw perforation of $14 \%$ and secondary screw perforation of $8 \%$ and avascular necrosis of $8 \%$. They concluded that fixation with PHILOS plate preserves achieved reduction and a good functional outcome can be expected. More accurate screw length measurement and shorter screw selection should prevent primary screw perforation.

Liu et al in 2010 concluded that treatment of proximal humeral fractures in elderly patients with application of PHILOS plate combined with injectable artificial bone as satisfactory, especially suitable for osteoporotic and comminuted proximal humeral fractures. They studied 17 patients from March 2007 to March 2009 with an average age 71 years (66 to 81 ). The clinical outcome was excellent in 9 patients, good in 6 , moderate in 2 cases.

\section{Conclusion}

Proximal humeral fractures managed by internal fixation with anatomic locking compression plates yields reliable results when provided the correct surgical technique. The anatomic locking compression plate is suitable for the stabilization of proximal humeral fractures (Neer's 2-part, 3-part and 4-part fractures and osteoporotic fracture) and can lead to a good functional outcome.

\section{References}

1. Rao TV, Venkataswamy K, Venkateswarulu J, et al. A study on surgical management of proximal humerus fractures by "PHILLOS" plate. J. Evolution Med. Dent. Sci. 2017;6(20):1578-1574

2. Lous U, Fredericka B. Fractures of proximal humerus. In: Rockwood CA, editor. Phildelphia: W.B. Sauders 1990, 278-334.

3. Cofield RH. Complications of operative fixation of proximal humeral fractures in patients with rheumatoid arthritis, J Shoulder Elbow Surg 2005;14:559.

4. Williams GR, Wong KL. Two part fractures management of proximal and distal humerus fractures. Ortho Clin North Am 2000;31(1):1-21.

5. Siddalingamurthy G, Ravi KHG, Abhilash GB, Darshan CK, mruthyunjaya et al. functionl outcome of proximal humerus interlocking system plating for displaced proximal humerus fractures in adults. J. Int J Orthop Sci 2017;3(2):32-37

6. Kulkarni S et al. Int J Res Orthop. 2017;3(2):304-309

7. Björkenheim JM, Pajarinen J, Savolainen V. Internal fixation of proximal humeral fractures with a locking compression plate: A retrospective evaluation of 72 patients followed for a minimum of 1 year. Acta Orthop Scand 2004;75:741-5.

8. Hessmann $\mathbf{M}$, Gehling $\mathrm{H}$, Gotzenl. Plate fixation of proximal humerus fracture with indirect reduction; surgical technique and results using the shoulder score. Injury 1999;30:453-62.

9. Wanner GA, Romero J, Hersche O. Internal fixation of displaced proximal humerus with two one-third tubular plates. J Trauma 2003;54;536-44.

10. Wijgman AJ, Roolker W, Patt TW. Open reduction and internal fixation of three and four part fracturesof the proximal humerus. J Bone Joint Surg Am 2002;84;191925.

11. Palvanen M, Kannus $\mathrm{P}$, Niemi $\mathrm{S}$. Update in the epidemiology of proximal humeral fractures. Clin Orthop
Relat Res 2006;442;87-92.

12. Shahid R, Mushtaq A, Northover J, Maqsood M. Outcome of proximal humerus fractures treated by PHILOS plate internal fixation. Experience of a district general hospital. Acta Orthop Belg 2008;74(5):602-8.

13. Brunner F, Sommer C, Bahrs C, Heuwinkel R, Hafner C, Rillmann $\mathrm{P}$, et al. Open reduction and internal fixation of proximal humerus fractures using a proximal humeral locked plate: a prospective multicenter analysis. J Orthop Trauma 2009;23(3):163-72.

14. Liu XW, Fu QG, Xu SG, Zhang CC, Su JC, Wang PF, et al. Application of PHILOS plate with injectable artificial bone for the treatment of proximal humeral fractures in elderly patients. Zhongguo Gushang 2010;23(3):180-2. 